\title{
Knowledge, attitudes, and practice of cervical cancer prevention among health workers in rural health centres of Northern Uganda
}

James Henry Obol ${ }^{1,2^{*}}$ (D), Sophia Lin ${ }^{1}$, Mark James Obwolo ${ }^{2}$, Reema Harrison ${ }^{1}$ and Robyn Richmond ${ }^{1}$

\begin{abstract}
Background: Cervical cancer is a leading cancer and cause of premature death among women in Uganda aged 15 to 44 years. To address the increasing burden of cervical cancer in Uganda, the Ministry of Health has adopted several strategies which include public education and advocacy. This study aims to assess knowledge, attitudes, and practice of cervical cancer prevention among health workers employed in rural health centres (HCs) III and IV in the Acholi sub-region of Northern Uganda.
\end{abstract}

Methods: We conducted a cross-sectional survey of nurses, midwives, and clinical officers between February and April 2019 using self-administered questionnaire. We sampled fifty-four HCs III and eight HCs IV. In Uganda, HCs are structured from $\mathrm{HCI}$ to $\mathrm{HCIV}$ and the health care package provided increases with increasing level of the HC. We used Epidata version 3.1 to create database and analysis was performed using Stata 16. Descriptive and logistic regression analyses were performed. Factors with $p$-values $\leq 0.05$ were considered as predictors of outcome.

Results: There were 286 participants who completed the questionnaire: Majority $(188,66 \%)$ were females. Nurses were 153 (54\%). 141 (75\%) female participants self-reported to have been screened for cervical cancer. 171 (60\%) participants had adequate knowledge of cervical cancer. 187 (66\%) participants had positive attitudes. Participants who indicated not to have ever received training on cervical cancer screening were less likely to have adequate knowledge ( $A O R=0.39,95 \% \mathrm{Cl} 0.21-0.71$ ). Participants who indicated not to have ever been trained on cervical cancer screening were less likely to have positive attitudes ( $\mathrm{AOR}=0.52,95 \% \mathrm{Cl} 0.28-0.97$ ).

Conclusion: Health workers from rural HCs in Uganda play crucial role in cervical cancer prevention as they can reach a wider community. Their significance in the prevention of cervical cancer points to the need for Uganda and other sub-Sahara Africa (SSA) countries to establish training to improve their knowledge, attitudes, and practical skills on cervical cancer screening. Furthermore, Uganda government should develop and disseminate guidelines for cervical cancer prevention to rural health workers to promote standardised cervical cancer prevention activities.

Keywords: Health workers, Cervical cancer, Knowledge, Attitudes, Practice, Northern Uganda, Rural health workers

\footnotetext{
*Correspondence: obolh@yahoo.com; j.obol@student.unsw.edu.au

'University of New South Wales School of Public Health and Community

Medicine, Kensington, NSW 2033, Australia

${ }^{2}$ Gulu University, Faculty of Medicine, P. O Box 166, Gulu, Uganda
}

(C) The Author(s). 2021 Open Access This article is licensed under a Creative Commons Attribution 4.0 International License, which permits use, sharing, adaptation, distribution and reproduction in any medium or format, as long as you give appropriate credit to the original author(s) and the source, provide a link to the Creative Commons licence, and indicate if changes were made. The images or other third party material in this article are included in the article's Creative Commons licence, unless indicated otherwise in a credit line to the material. If material is not included in the article's Creative Commons licence and your intended use is not permitted by statutory regulation or exceeds the permitted use, you will need to obtain permission directly from the copyright holder. To view a copy of this licence, visit http://creativecommons.org/licenses/by/4.0/ The Creative Commons Public Domain Dedication waiver (http://creativecommons.org/publicdomain/zero/1.0/) applies to the data made available in this article, unless otherwise stated in a credit line to the data. 


\section{Background}

Cervical cancer is the second most common form of cancer and a major cause of premature death among women aged 15 to 44 years worldwide [1]. There is great disparity in the incidence and mortality due to cervical cancer between developed and developing countries [1] with approximately $85 \%$ of incidence and $87 \%$ of deaths occurring in the less developed regions of the world [2]. Within the African region, Eastern and Southern Africa have the highest incidence and mortality rates of cervical cancer [1]. Furthermore, it has been estimated that from 2013, cervical cancer incidence and mortality will continue to rise in sub-Saharan Africa (SSA) over a period of 20 years [3]. This is in contrast with progress made by Northern Africa which has the lowest incidence and mortality due to cervical cancer in Africa [4]. Therefore, the burden of cervical cancer on the family and society cannot be ignored.

Cervical cancer can be prevented through vaccination with Human Papillomavirus (HPV) vaccine [5, 6]. Furthermore, precancerous cervical lesions remain detectable for up to 10 years or more before progressing to cervical cancer [7]. If precancerous cervical lesions are screened and removed, this can prevent development into cervical cancer $[7,8]$.

Several challenges create obstacles to the delivery of cervical cancer prevention programmes in SSA, including lack of diagnosis and treatment initiation due to limited service capacity $[6,9,10]$ and inadequate supplies and equipment needed for cervical cancer screening and treatment $[9,11]$. In addition to health system barriers, studies conducted among healthcare workers from tertiary hospitals in Eastern Africa have identified that most of them lack adequate knowledge of cervical cancer [8, $12,13]$, which results in inadequate detection of the disease among women with symptoms of cervical cancer $[14,15]$.

In Uganda, cervical cancer incidence has been rising at the rate of $1.8 \%$ per year over a period of 20 years between 1991 to 2010 [16]. This is due to high prevalence of HPV infection among women (10-40\%) [17], high parity [18], early initiation of sex for women [19] and high prevalence of Human immunodeficiency virus/Acquired immunodeficiency syndrome (HIV/AIDS) at $7.5 \%$ among women [20]. Despite increasing incidence and high prevalence of risk factors for cervical cancer in Uganda, the proportion of women who have ever been screened is low, estimated to be approximately $5-30 \%$ of women [21]. The uptake of the second dose of HPV vaccination for girls $10-14$ years is also low at $41 \%$ [22] against the target of $80 \%$ coverage [7].

To avert the increasing morbidity and mortality associated with cervical cancer globally, World Health Organization (WHO) with its partners have developed the triple-intervention strategy which seeks to ensure that by $2030,90 \%$ of HPV vaccination coverage, $70 \%$ of women being screened twice at least in their life time and $90 \%$ of women having access to cervical precancerous and cervical cancer treatment and palliative care services [23]. In Uganda, the Ministry of Health developed a Strategic Plan for Cervical Cancer Prevention and Control between 2010 and 2014 [7]. The Strategic Plan sets targets of reaching $90 \%$ of Ugandans with health education messages about cervical cancer, screening 80\% of women aged 25-49 years for cervical precancerous lesions, and treating those found positive for precancerous cervical lesions [7]. To achieve these targets by the year 2015, the Strategic Plan adopted several implementation strategies which include training health workers employed in HCs levels III and IV on cervical cancer screening using visual inspection with acetic acid (VIA) and treatment of precancerous lesions using cryotherapy [7].

Increased knowledge and positive attitudes of health workers to screen for cervical cancer are critical for cervical cancer prevention. Yet there is no evidence of the level of knowledge and attitudes towards cervical cancer and its prevention among health workers working in rural HCs in Uganda. Adequate knowledge of health workers is a determining factor for positive attitudes, and therefore, it is important that health workers knowledge is periodically assessed with the aim of addressing identified gaps [24]. Health workers are viewed as role models and should provide health education about cervical cancer to the populations they serve [25]. Therefore to achieve the WHO 90-70-90 triple-intervention strategy by $2030[23,26]$ and the goal of the Strategic Plan for Cervical Cancer Prevention and Control in Uganda [7], health workers must have adequate knowledge and positive attitude for them to implement cervical cancer prevention measures.

\section{Objective}

The objective of this study was to assess health workers' knowledge, attitudes, practice of cervical cancer prevention, and associated factors to help in the development of policy on cervical cancer in Uganda.

\section{Methods}

Study design

We conducted a cross-sectional survey of health workers working in rural HCs III and IV in Acholi sub-region of Northern Uganda using a self-administered questionnaire which was written in English.

\section{Setting}

The Acholi sub-region in Northern Uganda is bordered by South Sudan on the north, Karamoja on the east, 
Lango on the south and West Nile on the west. The total land size is around $28,000 \mathrm{~km}^{2}$ [27]. Acholi land in Northern Uganda experienced one of the world's most brutal arm conflicts between 1986 and 2006 [28, 29]. This armed conflict caused massive displacement of $90 \%$ of the Acholi population into internally displaced persons camps (IDPs) [28, 30, 31]. The armed conflict disrupted normal healthcare delivery as many health facilities were looted, destroyed or abandoned by the health workers in search of peace or employment elsewhere [32] due to fear of abduction [33]. At the time of the present study, cervical cancer screening and treatment services were provided by St. Mary's Hospital Lacor, the largest private not-for-profit missionary hospital; Gulu Regional Referral Hospital which is under Uganda Ministry of Health; and non-governmental organizations (NGOs), such as The AIDS Support Organization (TASO), Reproductive Health Uganda and Marie Stopes Uganda. These facilities are located within the urban area of Gulu Municipality.

The study was conducted among health workers who were working in rural HCs III and IV in the eight districts which form Acholi sub-region in Northern Uganda between 11th February to 18th April 2019. At the time of the study, the eight districts had sixty-four HC III and eight HC IV in rural areas [34] (Table 1).

\section{Organization of health facilities in Uganda}

The Uganda government operate a decentralised health care delivery system $[35,36]$. The primary health care facilities are controlled by the district local government (DLG), and the secondary and tertiary hospitals are semi-autonomous under direct supervision of Ministry of Health [35]. The primary health care facilities comprise of the village health teams (VHTs) which is regarded as a HC I, and then the formal health care system which are HC II - IV and general hospital [35]. The regional referral hospitals are secondary level health facilities while the national referral hospitals are tertiary health facilities [37].

Table 1 Numbers of HCs levels III and IV in each of the eight districts

\begin{tabular}{lll}
\hline District Name & Number of HC level III & Number of HC level IV \\
\hline Agago & 11 & 0 \\
Amuru & 10 & 1 \\
Gulu (Aswa county) & 6 & 1 \\
Kitgum & 8 & 1 \\
Lamwo & 8 & 2 \\
Nwoya & 3 & 0 \\
Omoro & 7 & 1 \\
Pader & 11 & 2 \\
\hline
\end{tabular}

The Uganda Ministry of Health has an established staffing structure for each level of health facility in Uganda [38]. In Uganda, the VHTs are community volunteers chosen by community members to provide healthcare services to their communities [39] and are regarded as HC I [36, 37, 39]. Each VHT serves about 1000 people or 25 households in a village [35, 40, 41], and they provided linkage between the community and the HCs [36, 39, 40, 42]. In addition to other functions, the VHTs are to raise awareness about and mobilise community members to participate in cervical cancer prevention activities [7].

A HC II is the lowest formal health care system [35, 42, 43] and serves a population of about 5000 people $[41,44]$. A HC II is managed by an Enrolled Nurse who work with one Enrolled Midwife [37], and provide only outpatient services $[35,42]$. The Strategic Plan stipulate that a HC II is to conduct health education, HPV vaccination and referral of women for cervical cancer screening [7].

The HC III is managed by a Senior Clinical Officer and serves a population of around 20,000 people [37, 41]. A Clinical Officer holds a diploma in clinical medicine and community health. Clinical officers carry out diagnosis, treatment as well as general management of patients. They also provide health education and carry out planning as well as drawing budgets for the $\mathrm{HCs}$ [45]. According to the Strategic Plan for Cervical Cancer Prevention and Control in Uganda, HC III is expected to perform the following functions: health education and counselling; HPV vaccination of target groups; cervical cancer screening using VIA; and referral of patients to HC IV or hospital for cryotherapy [7]. In HC III, the staff from which our research participants were drawn include 1 Senior Clinical Officer, 1 Clinical Officer, 1 Nursing Officer (Nursing), 2 Enrolled Midwives and 3 Enrolled Nurses [38].

The HC IV serves a population of about 100,000 people [41] and is managed by a senior medical officer [37]. According to the strategic plan, HC IV is expected to perform all the functions performed by $\mathrm{HC}$ III and, in addition, treat precancerous lesions using cryotherapy [7]. In HC IV, the staff establishment from which our research participants were also drawn is as follows: $1 \mathrm{Se}$ nior Nursing Officer, 1 Nursing Officer (Nursing), 1 Nursing Officer (Midwifery), 3 Enrolled Nurses, 3 Enrolled Midwives and 2 Clinical Officers [38].

The general hospital is the last referral health facility within a district and serves a population of 500,000 people $[35,41]$. The general hospital is managed by a Principal Medical Officer and has 1 Medical Officer Special Grade (Obstetrician and Gynaecology), 4 Medical Officers, 1 Principal Nursing Officer, 5 Senior Nursing Officers, 17 Nursing Officer Nursing, 46 Enrolled 
Nurses, 3 Nursing Officers (Midwifery), 25 Enrolled Midwives, 1 Senior Clinical Officer, and 5 Clinical Officers [37]. A general hospital performs all the functions of a HC IV in addition to treating precancerous lesion using loop electrosurgical excision procedure (LEEP), surgical treatment, referral for cytology, histological diagnosis and staging of cervical cancer [7].

\section{Health facilities and participants selections criteria}

We selected HC III and IV only for the survey because these are the health facilities where rural Ugandan women are to access cervical cancer prevention services [7] since about $72 \%$ of Ugandans live in rural areas [46]. The study participants comprised nurses, midwives and clinical officers working in rural HCs III and HCs IV. These participants were selected because the national Strategic Plan for Cervical Cancer Prevention and Control in Uganda specifies the need to train nurses, midwives and clinical officers to provide cervical cancer screening and treatment by 2015 [7]. Each participant must have worked at least for 1 year and has a valid practicing licence and not on study leave.

\section{Sample size and sampling procedure}

The sample size was calculated using the formula for a single population proportion for the survey [47], $\mathrm{n}=$ $\left(\mathrm{z}^{2} \mathrm{pq} / \mathrm{d}^{2}\right)$, where $\mathrm{n}$ is the desired sample size; $\mathrm{z}$ is the $90 \%$ confidence interval (CI) which was 1.645; $\mathrm{p}$ is the proportion of the health workers with an adequate knowledge, attitude and practice of cervical cancer prevention, set at 0.5 since they were unknown; and $d$ is the level of precision desired, set at 0.05 . The total sample size was $(1.645)^{2} 0.5(1-0.5) /(0.05)^{2}=271$.

After increasing the calculated sample size to account for a $5 \%$ non-response or withdrawal of consent from the study, the final sample size was estimated as 285 health workers. We sampled 54 out of $64 \mathrm{HCs}$ level III based on the Ministry of Health national health facility master list 2018 [34]. The 54 HCs III were selected as follows: All HC III names were listed alphabetically and assigned numbers from 1 to 64 . We generated 54 random numbers between 1 and 64 using software [48] and these numbers were matched with the one for the $\mathrm{HCs}$ giving us the names of $\mathrm{HCs}$ for the survey. The study was advertised in each of the HCs and potential research participants were briefed about the study. Consenting research participants were consecutively recruited from each of the sampled HCs.

\section{Operational definitions and measurements}

Knowledge: Knowledge was evaluated using 25 question items with a "yes" or "no" response. Each correct response was awarded one mark and a wrong response given zero marks. There were 9 questions on cervical cancer risk factors; 5 on cervical cancer signs and symptoms; and 11 questions on cervical cancer prevention and control. The scores from all the 25 items were summed and the mean sum of total scores was calculated. Any participant who scored equal or above the mean ( $\geq 18$ marks) was categorised as having adequate level of cervical cancer knowledge and participants who scored below the mean (less than 18 marks) were categorised as having inadequate knowledge for cervical cancer.

\section{Attitudes}

We assessed attitudes using 13 statement items measured on 5 -point Likert scale (1 strongly disagree, 2 disagree, 3 neutral, 4 agree and 5 strongly agree) to measure proxy variables of willingness to participate in cervical cancer training, screening, and other prevention activities. To sum the scores, individual responses from statements which were formulated negatively were transformed to positive statements. The participants' scores from all the 13 statements were summed-up and the average score was calculated. Participants who scored equal or above the mean $(\geq 56)$ were considered as having positive attitudes while participants who scored below the mean were considered as having negative attitudes.

The scoring methods were adopted as there are no standardised test questions with cut-off values for participants' knowledge and attitudes in this region. However, these scores reflect participants' knowledge and attitudes towards participation in cervical cancer training, and prevention activities.

\section{Data sources and measurements}

Data was collected using a self-administered structured questionnaire (see Additional file 1) which was written in English. The questions for the questionnaire were selected based on the review of relevant literature which address the study objectives. These includes the Uganda Strategic Plan for the Prevention and Control of Cervical Cancer [7] and other studies conducted within Uganda, SSA and elsewhere $[8,13,18,49-58]$. The questionnaire consisted of five parts. The first part asked about demographic factors including age, gender, qualifications, HC level, whether HC staff received training to conduct cervical cancer screening or not, and the number of years the participant had worked. We also obtained data on HC characteristics; namely, availability of guideline for HPV vaccination and cervical cancer screening; whether $\mathrm{HC}$ received funding for cervical cancer activities and health education material; and whether health workers conducted outreach health education in the community. The second section sought information on when they had heard of cervical cancer for the first-time and the 
sources of information. The third part of the questionnaire obtained information about cervical cancer screening uptake by female health workers and the reasons for not undertaking cervical cancer screening. For male health workers, we asked whether they would encourage their partners to get screened for cervical cancer. Part four of the questionnaire contained questions about knowledge on cervical cancer risk factors, signs, symptoms, and methods of cervical cancer prevention. We included questions about cervical cancer myths to test the health workers. Questions in part five asked information about participants' attitudes towards participation in cervical cancer training, and prevention activities.

\section{Quality control}

The following quality control procedures were taken to minimise bias: The principal investigator (PI) trained the research assistants on data collection tool, consent procedure, confidentiality, and privacy. The PI together with research assistants pre-tested the questionnaire among 15 health workers (nurses, midwives, and clinical officers) working in three HCs III in Gulu Municipality. The information collected during pre-testing was used to validate the content and to modify the questionnaire to improve clarity and ease of understanding before using the questionnaire in the study. The information obtained from the 15 health workers during pre-testing the questionnaire was excluded in the final analysis reported in this manuscript. The PI and research assistant closely monitored filling in the questionnaires to ensure that the questionnaires were correctly filled, and participants do not discuss answers among themselves or search information online.

\section{Data management and analysis}

The PI entered the data into Epidata 3.1 [59] database and analysed using Stata version 16 [60]. Participants ages were categorised using interval of 5 years while participants' number of years of working as a health worker was categorised using interval of 4 years. Knowledge and attitudes were categorised as described under the operational definitions of outcomes measures. One participant did not provide answer for knowledge or attitude and was omitted in the analysis of knowledge and attitude. Categorical variables were summarised and displayed in tables with frequencies and percentages. Chi square test and Fisher's exact test were used to compare proportions among health worker qualifications and score for adequate knowledge of cervical cancer, cervical cancer risk factors, signs and symptoms, and prevention methods. Chi square test and Fisher's exact test were used to compare proportions among health worker qualifications and average score for attitudes. Bivariate analyses were performed to examine the relationship between dependent and independent variables using logistic regression analysis. Determinant of knowledge and attitudes were investigated using multivariate logistics regression analysis using enter methods. Any variable with a $p$-value $\leq 0.05$ was considered a statistically significant predictor of adequate knowledge and positive attitudes.

\section{Results \\ Study population}

A total of 301 health workers were contacted for participation in the study. Ten health workers declined to participate in the study expressing disinterest. Five participants did not return their questionnaire when they were called to a medical emergency or delivery and we made effort to retrieve the questionnaires, but we were unsuccessful. These participants were regard to have withdrawn their consent for further participation in the study. This leaves us with 286 health workers who filled and handed back the questionnaire.

\section{Demographic characteristics of respondents}

A total of 286 participants aged 21-57 years were surveyed with a mean age of 35 years. Just over half of the participants were nurses $(n=153,54 \%)$. Most participants were female $(n=188,66 \%)$. The average years of work experience was 9.8 (range 1-38 years) with most participants having between 5 and 9 years' experience $(n=113,40 \%)$. Most of the participants were from HC III $(n=222,78 \%)$. A third of the participants were ever trained to conduct cervical cancer screening $(n=93$, $33 \%)$. Less than half of the participants were conducting outreach health education about cervical cancer in the community ( $n=128,45 \%$ ). Health workers who indicated that their HC had HPV vaccination guideline were 205 (74\%). Health workers who indicated that their HCs had guideline for cervical cancer screenings were 58 (21\%). Table 2 summarises the demographic characteristics of the study participants.

\section{Practice of cervical cancer prevention}

There were 141 (75\%) female health workers who selfreported to have ever been screened for cervical cancer, while 87 (91\%) of the male health workers indicated they had encouraged their partners to be screened for cervical cancer. Figure 1 summarises reasons for not undertaking cervical cancer screening by 47 female health workers.

\section{Knowledge about cervical cancer}

Participants had heard about cervical cancer from these sources: through the media 98 (35\%), during training for current job 146 (51\%), from colleagues at work $11(4 \%)$, during in-service training $23(8 \%)$ and other sources 6 (2\%). We found that $171(60 \%)$ participants had 
Table 2 Demographic characteristics of the health workers

\begin{tabular}{|c|c|c|}
\hline Variables & Frequency & Percent \\
\hline \multicolumn{3}{|c|}{ Health workers qualifications $(n=286)$} \\
\hline Nurses & 153 & 54 \\
\hline Midwife & 81 & 28 \\
\hline Clinical Officer & 52 & 18 \\
\hline \multicolumn{3}{|c|}{ Gender of health workers $(n=286)$} \\
\hline Male & 98 & 34 \\
\hline Female & 188 & 66 \\
\hline \multicolumn{3}{|c|}{ Health centre level of health workers $(n=286)$} \\
\hline Health centre level IV & 64 & 22 \\
\hline Health centre level III & 222 & 78 \\
\hline \multicolumn{3}{|c|}{ Number of years employed as a health worker $(n=281)$} \\
\hline $1-4$ years & 54 & 19 \\
\hline $5-9$ years & 113 & 40 \\
\hline 10-14 years & 53 & 19 \\
\hline $15+$ years & 61 & 22 \\
\hline \multicolumn{3}{|c|}{ Age group of health workers $(n=280)$} \\
\hline $21-25$ years & 19 & 7 \\
\hline 26-30 years & 76 & 27 \\
\hline $31-35$ years & 72 & 26 \\
\hline $36-40$ years & 52 & 18 \\
\hline $41+$ years & 61 & 22 \\
\hline \multicolumn{3}{|c|}{ Health worker trained to conduct cervical cancer screening ( $n=283$ ) } \\
\hline Yes & 93 & 33 \\
\hline No & 190 & 67 \\
\hline \multicolumn{3}{|c|}{ HC has education material about cervical cancer $(n=284)$} \\
\hline No & 200 & 70 \\
\hline Yes & 84 & 30 \\
\hline \multicolumn{3}{|c|}{ Health worker conducts outreach health education in the community $(n=283)$} \\
\hline Yes & 128 & 45 \\
\hline No & 155 & 55 \\
\hline \multicolumn{3}{|c|}{ HC receives fund for cervical cancer activities $(n=282)$} \\
\hline No & 273 & 97 \\
\hline Yes & 9 & 3 \\
\hline \multicolumn{3}{|c|}{ HC has guideline for cervical cancer screening $(n=281)$} \\
\hline Yes & 58 & 21 \\
\hline No & 223 & 79 \\
\hline \multicolumn{3}{|c|}{ HC has HPV vaccination guideline $(n=276)$} \\
\hline Yes & 205 & 74 \\
\hline No & 71 & 26 \\
\hline \multicolumn{3}{|c|}{ Participant knew period covered by strategic plan for cervical cancer prevention and control in Uganda } \\
\hline Yes & 5 & 2 \\
\hline No & 281 & 98 \\
\hline
\end{tabular}

HC Health centre, HPV Human Papillomavirus 


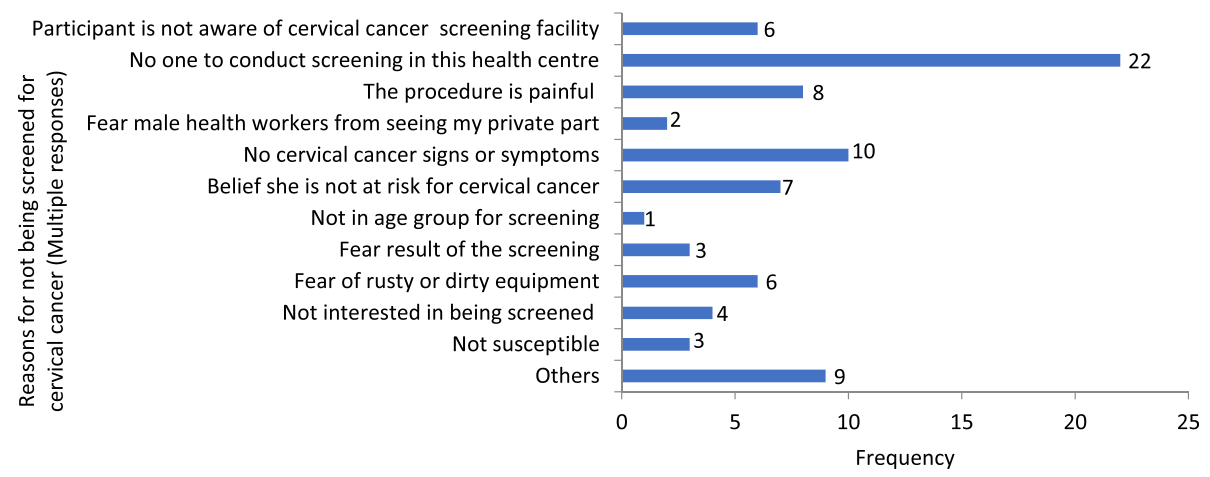

Fig. 1 Reasons for not undertaking cervical cancer screening by 47 female health workers

adequate knowledge i.e., they scored equal to or above mean $(\geq 18)$ out of a total of 25 . Overall score for adequate knowledge about cervical cancer among nurses, midwives and clinical officers was not significant $h$ $\left(\mathrm{X}^{2}=0.16, p\right.$-value $\left.=0.93\right)$. However, there were associations among the following knowledge variables and health workers' qualification: tobacco smoking and risk factor for cervical cancer $\left(\mathrm{X}^{2}=8.37, p\right.$-value $\left.=0.02\right)$; unexplained weight loss as sign for cervical cancer $\left(\mathrm{X}^{2}=\right.$ 6.46, $p$-value $=0.04$ ); avoiding multiple deliveries $/$ births as method for cervical cancer prevention $\left(\mathrm{X}^{2}=10.11, p\right.$ value $=0.01$ ); and knowing correct age group for screening using VIA according to Uganda Ministry of Health $\left(\mathrm{X}^{2}=6.23, p\right.$-value $\left.=0.04\right)$.

Nearly all participants $(n=283,99 \%)$ correctly identified having multiple sexual partners as a risk factor for cervical cancer. Tobacco smoking as a risk factor for cervical cancer was indicated by 120 (42\%). Long term use of oral contraceptives as a risk factor for cervical cancer was identified by 65 (23\%). Infection with Chlamydia trachomatis as a risk factor for cervical cancer was identified by 142 (50\%). Most participants $(n=266,93 \%)$ indicated that bleeding after sexual intercourse is a sign of cervical cancer. Participants knew about prevention of cervical cancer such as: avoiding prolonged use of oral contraceptives pills $(n=81,28 \%)$ and abstaining from tobacco use $(n=$ 133, 47\%). There were 277 (97\%) participants who knew that early screening is a preventive measure, but only $46(16 \%)$ knew the correct age group for cervical cancer screening using VIA based on the Uganda Ministry of Health guideline (Table 3).

\section{Misconceptions about cervical cancer risk factors, signs, and symptoms}

Participants had misconceptions about cervical cancer risk factors. Most participants believed that family history was a risk factor for cervical cancer $(n=209$, $73 \%)$; half $(n=144,50 \%)$ believed cervical cancer was caused by infection with Herpes simplex virus. Few believed excessive alcohol consumption was a risk factor $(n=48,17 \%)$. There were also some misconceptions regarding the signs and symptoms of cervical cancer. Two thirds believed abdominal pain was a sign of cervical cancer $(n=192,67 \%) ; 35$ participants (12\%) thought headaches were a symptom, and 18 (6\%) thought night sweats were also associated (Table 4).

\section{Attitudes towards participation in cervical cancer training, and prevention activities}

There were 187 (66\%) health workers who had positive attitudes i.e., they scored equal or above mean $(\geq 56$ out of 65). There was no association between attitudes and health workers qualification $\left(X^{2}=3.16, p\right.$-value $\left.=0.206\right)$. A total of $250(88 \%)$ participants strongly agreed that they would be happy to see that their daughters or sisters were immunised against HPV. Participants who strongly agreed that they would participate in training for cervical cancer prevention if organised by Uganda Ministry of Health were 199 (70\%). There were 256 (90\%) who strongly disagreed with the statement that cervical cancer is not a serious health problem, so screening is just a burden. There were 214 (75\%) participants who strongly agreed that they were more likely to screen women for cervical cancer if they were trained and provided with equipment and consumables. Table 5 summarises participant's responses to the various statements about participation in cervical cancer training, and prevention activities.

\section{Factors associated with adequate knowledge about} cervical cancer among health workers

In the multivariate logistic regression model, participants who indicated not to have ever received training to conduct cervical cancer screening were $61 \%$ less likely to have an adequate knowledge score ( $\mathrm{AOR}=0.39,95 \% \mathrm{CI}$ $0.21-0.72, p$-value $=0.00)($ Table 6$)$. 
Table 3 Knowledge about cervical cancer risk factors, signs and symptoms, and prevention and control stratified by health worker's qualifications

\begin{tabular}{|c|c|c|c|c|c|c|}
\hline Variables & $\begin{array}{l}\text { Total, } N=285 \\
\text { (\%) }\end{array}$ & $\begin{array}{l}\text { Nurses, } N=153 \\
(53 \%)\end{array}$ & $\begin{array}{l}\text { Midwives, } N=80 \\
(28 \%)\end{array}$ & $\begin{array}{l}\mathrm{CO}, N=52 \\
(18 \%)\end{array}$ & $x^{2}$ & $\begin{array}{l}p- \\
\text { value }\end{array}$ \\
\hline Adequate knowledge score $\geq$ mean (18 marks) & $171(60)$ & $93(61)$ & $48(60)$ & $30(58)$ & 0.16 & 0.93 \\
\hline \multicolumn{7}{|l|}{ Risk factors for cervical cancer } \\
\hline Infection with HPV & $244(85)$ & $130(85)$ & $66(82.5)$ & $48(92)$ & 2.57 & 0.28 \\
\hline Smoking cigarette & $120(42)$ & $54(35)$ & $36(45)$ & $30(58)$ & 8.37 & 0.02 \\
\hline Infection with HIV & $235(82)$ & $124(81)$ & $66(82.5)$ & $45(87)$ & 0.81 & 0.69 \\
\hline Having multiple deliveries & $189(66)$ & $110(72)$ & $50(62.5)$ & $29(56)$ & 5.24 & 0.07 \\
\hline Early age at first delivery & $177(62)$ & $92(60)$ & $55(69)$ & $30(58)$ & 2.18 & 0.35 \\
\hline Early age at sexual debut & $264(92)$ & $139(91)$ & $74(93$ & $51(98)$ & 2.97 & 0.22 \\
\hline Long-term use of oral contraceptives pills & $65(23)$ & $35(23)$ & $21(26)$ & $9(17)$ & 1.43 & 0.49 \\
\hline Infection with Chlamydia trachomatis & $142(50)$ & $83(54)$ & $35(44)$ & $24(46)$ & 2.66 & 0.26 \\
\hline Having multiple sexual partners & $283(99)$ & $153(100)$ & $78(98)$ & $52(100)$ & 5.16 & 0.08 \\
\hline \multicolumn{7}{|l|}{ Signs and symptoms of cervical cancer } \\
\hline Foul-smelling vaginal discharge & $237(83)$ & $124(81)$ & $69(86)$ & $44(85)$ & 1.11 & 0.58 \\
\hline Bleeding after menopause & $260(91)$ & $138(90)$ & $73(91)$ & $49(94)$ & 0.79 & 0.70 \\
\hline Bleeding after sexual intercourse & $266(93)$ & $143(93)$ & $73(91)$ & $50(96)$ & 1.22 & 0.54 \\
\hline Abnormal vaginal bleeding between period & $237(83)$ & $126(82)$ & $67(84)$ & $44(85)$ & 0.17 & 0.92 \\
\hline Unexplained weight loss & $174(61)$ & $95(62)$ & $41(51)$ & $38(73)$ & 6.46 & 0.04 \\
\hline \multicolumn{7}{|l|}{ Prevention and control of cervical cancer } \\
\hline Vaccination against HPV & $282(99)$ & $152(99)$ & $78(97.5)$ & $52(100)$ & 2.40 & 0.30 \\
\hline $\begin{array}{l}\text { Correct age group for HPV vaccination according to Uganda Ministry } \\
\text { of Health }\end{array}$ & $250(87)$ & $138(90)$ & $68(84)$ & $44(85)$ & 2.33 & 0.31 \\
\hline Using condom during sexual encounter & $234(82)$ & $126(82)$ & $66(82.5)$ & $42(81)$ & 0.08 & 0.96 \\
\hline Avoiding multiple sexual partners & $280(98)$ & $149(97)$ & $79(98)$ & $52(100)$ & 1.37 & 0.74 \\
\hline Delaying initiation of sex after 18 years & $220(77)$ & $114(75)$ & $62(77.5)$ & $44(85)$ & 2.26 & 0.32 \\
\hline Male circumcision & $249(87)$ & $134(88)$ & $68(85)$ & $47(90)$ & 0.84 & 0.66 \\
\hline Avoiding prolong use of oral contraceptive pills & $81(28)$ & $41(27)$ & $28(35)$ & $12(23)$ & 2.63 & 0.27 \\
\hline Avoiding smoking cigarette & $133(47)$ & $64(42)$ & $40(50)$ & $29(56)$ & 3.53 & 0.17 \\
\hline Avoiding multiple deliveries/births & $193(68)$ & $113(74)$ & $54(67.5)$ & $26(50)$ & 10.11 & 0.01 \\
\hline Early screening & $277(97)$ & $148(97)$ & $78(97.5)$ & $51(98)$ & 0.30 & 0.86 \\
\hline $\begin{array}{l}\text { Correct age group for screening using VIA according to Uganda } \\
\text { Ministry of Health }\end{array}$ & $46(16)$ & $19(12)$ & $20(25)$ & $7(13)$ & 6.23 & 0.04 \\
\hline
\end{tabular}

$\mathrm{X} 2=$ chi-square test, $\mathrm{df}=2$, Significant results are bolded, $C O$ Clinical Officers

Table 4 Misconception about cervical cancer risk factors, signs and symptoms stratified by health workers' qualifications

\begin{tabular}{|c|c|c|c|c|c|c|}
\hline Variables & $\begin{array}{l}\text { Total } N=285 \\
(\%)\end{array}$ & $\begin{array}{l}\text { Nurses, } N=153 \\
(53 \%)\end{array}$ & $\begin{array}{l}\text { Midwives, } N=80 \\
(28 \%)\end{array}$ & $\begin{array}{l}\mathrm{CO}, N=52 \\
(18 \%)\end{array}$ & $x^{2}$ & $P$-value \\
\hline \multicolumn{7}{|c|}{ Misconception about cervical cancer risk factors } \\
\hline $\begin{array}{l}\text { Infection with herpes simplex virus-2 } \\
\text { (HSV-2) }\end{array}$ & $144(51)$ & $75(49)$ & $40(50)$ & $29(56)$ & 0.72 & 0.70 \\
\hline Over consumption of Alcohol & $48(17)$ & $23(15)$ & $14(17.5)$ & $11(21)$ & 1.07 & 0.59 \\
\hline Having a family history of cervical cancer & $209(73)$ & $120(78)$ & $56(70)$ & $33(63)$ & 5.08 & 0.08 \\
\hline \multicolumn{7}{|c|}{ Misconception about cervical cancer signs and symptoms } \\
\hline Abdominal pain & $192(67)$ & $101(66)$ & $52(65)$ & $39(75)$ & 1.71 & 0.43 \\
\hline Having headache & $35(12)$ & $24(16)$ & $6(7.5)$ & $5(10)$ & 3.69 & 0.16 \\
\hline Having a lot of night sweat & $18(6)$ & $7(5)$ & $7(9)$ & $4(8)$ & 1.75 & 0.42 \\
\hline
\end{tabular}

$\mathrm{X} 2=$ chi-square test, $\mathrm{df}=2$, CO Clinical Officers 
Table 5 Participants' attitudes towards participation in cervical cancer training, and prevention activities in Northern Uganda

\begin{tabular}{|c|c|c|c|c|c|c|}
\hline Statements & $\mathbf{N}$ & $\begin{array}{l}\text { Strongly } \\
\text { Disagree (1) }\end{array}$ & $\begin{array}{l}\text { Disagree } \\
\text { (2) }\end{array}$ & $\begin{array}{l}\text { Neutral } \\
(3)\end{array}$ & $\begin{array}{l}\text { Agree } \\
\text { (4) }\end{array}$ & $\begin{array}{l}\text { Strongly } \\
\text { Agree (5) }\end{array}$ \\
\hline I always advise my patients to screen for cervical cancer & 283 & $10(4)$ & $2(1)$ & $21(7)$ & $97(34)$ & $153(54)$ \\
\hline I discuss cervical cancer in our staff meeting & 279 & $39(14)$ & $73(26)$ & $49(18)$ & $87(31)$ & $31(11)$ \\
\hline I will be happy to see that my children/sister are immunised against HPV & 284 & $8(3)$ & $0(0)$ & $2(1)$ & $24(8)$ & $250(88)$ \\
\hline Cervical cancer is not a serious health problem, so screening is just a burden & 285 & $256(90)$ & $18(6)$ & $2(1)$ & $3(1)$ & $6(2)$ \\
\hline $\begin{array}{l}\text { Even if we screen and find a woman with precancerous lesion, there is nothing we } \\
\text { can do }\end{array}$ & 280 & $198(71)$ & $61(22)$ & $10(3)$ & $3(1)$ & $8(3)$ \\
\hline I do not think it is necessary to screen for cervical cancer in our health facility & 285 & $236(83)$ & $30(10)$ & $0(0)$ & $3(1)$ & $16(6)$ \\
\hline Government has not shown commitment about cervical cancer so why bother us & 284 & $159(56)$ & $69(24)$ & $23(8)$ & $17(6)$ & $16(6)$ \\
\hline $\begin{array}{l}\text { I am not interested in cervical cancer prevention because partners/NGOs do their } \\
\text { work without developing our capacity to implement cervical cancer control } \\
\text { program on our own }\end{array}$ & 284 & $131(46)$ & $81(28)$ & $28(10)$ & $28(10)$ & $16(6)$ \\
\hline $\begin{array}{l}\text { I will participate in cervical cancer prevention program if I am going to be paid } \\
\text { money cash }\end{array}$ & 282 & $90(32)$ & $102(36)$ & 49 (17) & $19(7)$ & $22(8)$ \\
\hline $\begin{array}{l}\text { I am willing to participate in a training for cervical cancer prevention if organised by } \\
\text { Gulu University \& University of New South Wales - Australia }\end{array}$ & 283 & $8(3)$ & $8(3)$ & $15(5)$ & $61(22)$ & $191(67)$ \\
\hline $\begin{array}{l}\text { I am willing to participate in a training for cervical cancer prevention if organised by } \\
\text { Ministry of Health Uganda }\end{array}$ & 283 & $4(1)$ & $3(1)$ & $11(4)$ & $66(23)$ & $199(70)$ \\
\hline $\begin{array}{l}\text { I am willing to participate in a training for cervical cancer prevention if organised by } \\
\text { NGOs }\end{array}$ & 282 & $5(2)$ & $6(2)$ & $20(7)$ & 77 (27) & $174(62)$ \\
\hline $\begin{array}{l}\text { I am more likely to screen women for cervical cancer if I am trained and given } \\
\text { equipment \& consumables }\end{array}$ & 284 & $8(3)$ & $1(0)$ & $2(1)$ & $59(21)$ & $214(75)$ \\
\hline
\end{tabular}

Factors associated with positive attitudes towards participation in cervical cancer training, and prevention activities

Participants who indicated not to have ever been trained to conduct cervical cancer screening were $48 \%$ time less likely to have positive attitudes towards participation in cervical cancer training, and prevention activities $(\mathrm{AOR}=0.52, \quad 95 \% \quad \mathrm{CI}: \quad 0.28-0.97, \quad p$-value $=0.04)$ (Table 7).

\section{Discussion}

This study provides information on knowledge, attitudes, and practice of cervical cancer prevention among health workers from rural $\mathrm{HCs}$ in eight districts in Uganda. Health workers from rural HCs play a significant role in reaching a wider community with information regarding cervical cancer prevention measures. Though studies on knowledge, attitude and practice of cervical cancer prevention among health workers have been conducted and discussed earlier in Uganda [8] and other SSA countries $[13,53-58,61,62]$, this study is the first comprehensive one involving health workers who are based in rural HCs. This study provides valuable information which is useful in formulating comprehensive cervical cancer prevention strategies in Uganda and other SSA countries.

In our study we found a higher proportion of participants with adequate knowledge about cervical cancer compared to a study conducted in Cote d'Ivoire (55.7\%) [53]. The participants in the study by Tchounga et al included student midwives [53] and this could have impacted on the level of knowledge score compared to our study in which participants were all qualified and employed.

However, knowledge was lower in our study compared to studies conducted in Ethiopia (86.9\%) [54], India (85\%) [63], Nigeria (98.6\%) [58], Pakistan (88.1\%) [64] and Burundi (76.3\%) [55]. Unlike our study in which participants had to score at least 18 or more out of 25 , the study conducted in India categorised participants as having good knowledge if participants were able to provide any three correct known risk factors for cervical cancer [63]. The studies conducted in Ethiopia [54], Nigeria [58] and Pakistan [64] all used scores of $50 \%$ or more to categorise participants as having good knowledge. The study conducted in Burundi had participants who were general medical practitioners [55] and are expected to have better knowledge due to their training on cervical cancer than the participants in our study who had lower levels of professional training. Therefore, there is a need to standardise scoring for adequate knowledge for cervical cancer among health workers to ensure that knowledge can be measured uniformly across countries. Lowering the cut-off value for knowledge to $50 \%$ as indicated in most of these studies would result into many health workers being categorised as having adequate knowledge. This could result in undesirable consequences as most of these 
Table 6 Bivariate and multivariate analysis of factors associated with adequate knowledge scores about cervical cancer among health workers

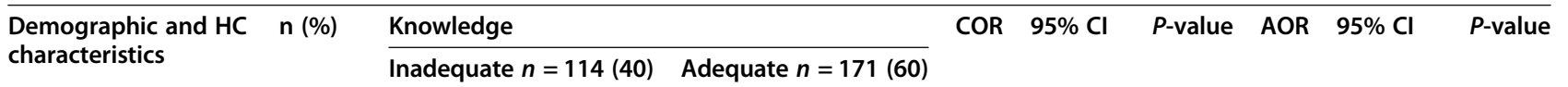

Health workers qualifications $(n=285)$

$\begin{array}{llll}\text { Nurses } & 153(54) & 60(39) & 93(61) \\ \text { Midwife } & 80(28) & 32(40) & 48(60) \\ \text { Clinical Officer } & 52(18) & 22(42) & 30(58)\end{array}$

Gender of health workers $(n=286)$

$\begin{array}{llllllllll}\text { Male } & 98(34) & 42(43) & 56(57) & 1 & & 1 & \\ \text { Female } & 187(66) & 72(39) & 115(61) & 1.20 & 0.73-1.97 & 0.48 & 1.43 & 0.74-2.76 & 0.28\end{array}$

Health centre level of health workers $(n=286)$

Health centre level IV 64 (22) 26 (41) 38 (59)

Health centre level III $221(78) \quad 88(40) \quad 133(60)$

\begin{tabular}{lll}
\multicolumn{3}{l}{ loyed as a health worker $(\boldsymbol{n = 2 8 1 )}$} \\
$54(19)$ & $27(50)$ & $27(50)$ \\
$112(40)$ & $42(37.5)$ & $70(62.5)$ \\
$53(19)$ & $20(38)$ & $33(62)$ \\
$61(22)$ & $24(39)$ & $37(61)$
\end{tabular}

$27(50)$

$70(62.5)$

$33(62)$

$37(61)$

$\begin{array}{llllll}1 & & & & & \\ 0.97 & 0.56-1.68 & 0.91 & 1.15 & 0.57-2.30 & 0.70 \\ 0.88 & 0.46-1.67 & 0.69 & 0.98 & 0.45-2.15 & 0.97\end{array}$

$10(53)$

$41(54)$

$44(62)$

$32(62)$

$38(62)$
1

$\begin{array}{llllll}1.03 & 0.59-1.82 & 0.91 & 1.10 & 0.56-2.16 & 0.78\end{array}$

\begin{tabular}{llllll}
1 & & \multicolumn{1}{c}{1} & & \\
1.67 & $0.86-3.21$ & 0.13 & 2.07 & $0.84-5.11$ & 0.11 \\
1.65 & $0.76-3.56$ & 0.20 & 1.17 & $0.38-3.62$ & 0.79 \\
1.54 & $0.74-3.23$ & 0.25 & 0.91 & $0.22-3.65$ & 0.89
\end{tabular}

$\begin{array}{llllll}1.05 & 0.39-2.89 & 0.92 & 0.83 & 0.24-2.88 & 0.77\end{array}$

$\begin{array}{lllllll}1.47 & 0.53-4.07 & 0.46 & 0.87 & 0.21-3.57 & 0.85\end{array}$

$1.44 \quad 0.50-4.16 \quad 0.50 \quad 1.32 \quad 0.30-5.72 \quad 0.71$

$1.49 \quad 0.53-4.20 \quad 0.45 \quad 1.64 \quad 0.29-9.31 \quad 0.58$

Age group of health workers $(n=280$

$\begin{array}{llll}21-25 \text { years } & 19(7) & 9(47) & 10(53) \\ 26-30 \text { years } & 76(27) & 35(46) & 41(54) \\ 31-35 \text { years } & 71(25) & 27(38) & 44(62) \\ 36-40 \text { years } & 52(19) & 20(38) & 32(62) \\ 41+\text { years } & 61(22) & 23(38) & 38(62)\end{array}$

Healthcare worker trained to conduct cervical cancer screening $(n=282)$

\begin{tabular}{|c|c|c|c|}
\hline Yes & 93 (33) & $26(28)$ & $67(72)$ \\
\hline No & $189(67)$ & $85(45)$ & $104(55)$ \\
\hline
\end{tabular}

$104(55)$

HC has education material about cervical cancer $(n=283)$

\begin{tabular}{|c|c|c|c|}
\hline Yes & $84(30)$ & $33(39)$ & $51(61)$ \\
\hline No & $199(70)$ & $80(40)$ & $119(60)$ \\
\hline
\end{tabular}

Health worker conduct outreach health education in the community $(n=283)$
Yes
$128(45) \quad 45(35)$
83 (65)
No
$154(55) \quad 69(45)$
$85(55)$

HC has guideline for cervical cancer screening $(n=281)$

\begin{tabular}{|c|c|c|c|}
\hline Yes & $58(21)$ & $18(31)$ & $40(69)$ \\
\hline No & $222(79)$ & $94(42)$ & $128(58)$ \\
\hline
\end{tabular}

HC has HPV vaccination guideline $(n=275)$

\begin{tabular}{|c|c|c|c|c|c|c|c|c|c|}
\hline Yes & $204(74)$ & $76(37)$ & $128(63)$ & 1 & & & 1 & & \\
\hline No & $71(26)$ & $33(46)$ & $38(54)$ & 0.68 & $0.40-1.18$ & 0.17 & 0.68 & $0.38-1.25$ & 0.21 \\
\hline
\end{tabular}

COR Crude Odds Ratio, AOR Adjusted Odds Ratio. Adjusted for each demographic characteristic. Bolded figures indicate statistically significant variables at $p \leq$ 0.05 . HC Health centre. We used Hosmer-Lemeshow goodness-of-fit test to check if our final model had fitted the data perfectly well and the $p$-value $=0.44$ from the Hosmer-Lemeshow's goodness-of-fit test is an indicator that our model fitted the data well. The few missing data on demographic characteristics were not dropped from the analysis since the missing rates were less than $5 \%$ and were considered inconsequential based on Schafer (1999)

health workers will not have adequate information to provide to audience. This is because health workers play a major role in communicating health behaviour to population which would require them to be well informed to pass accurate information about cervical cancer to the audience.

Most of our participants knew that early screening for cervical cancer is important in the prevention of cervical 
Table 7 Bivariate and multivariate analysis of demographic characteristics associated with positive attitudes towards participation in cervical cancer training, and prevention activities by health workers $(n=285)$

\begin{tabular}{|c|c|c|c|c|c|c|c|c|c|}
\hline \multirow{2}{*}{$\begin{array}{l}\text { Demographic } \\
\text { characteristics }\end{array}$} & \multirow[t]{2}{*}{ n (\%) } & Attitudes & & \multirow[t]{2}{*}{ COR } & \multirow[t]{2}{*}{$95 \% \mathrm{Cl}$} & \multirow[t]{2}{*}{$p$-values } & \multirow[t]{2}{*}{ AOR } & \multirow[t]{2}{*}{$95 \% \mathrm{Cl}$} & \multirow[t]{2}{*}{$p$-value } \\
\hline & & Negative $n=98(34 \%)$ & Positive $n=187(66 \%)$ & & & & & & \\
\hline
\end{tabular}

Health workers qualifications $(\boldsymbol{n}=\mathbf{2 8 5})$

$\begin{array}{llll}\text { Nurses } & 153(54) & 47(31) & 106(69) \\ \text { Midwife } & 80(28) & 28(35) & 52(65) \\ \text { Clinical Officer } & 52(18) & 23(44) & 29(56)\end{array}$

Gender of health workers $(n=285)$

\begin{tabular}{|c|c|c|c|}
\hline Male & 98 (34) & 37 (38) & $61(68)$ \\
\hline Female & $187(66)$ & $61(33)$ & 126 \\
\hline
\end{tabular}

Health centre level of health workers $(n=285)$

$\begin{array}{llll}\text { Health centre level IV } & 64(22) & 24(37.5) & 40(62.5) \\ \text { Health centre level III } & 221(78) & 74(33) & 147(67)\end{array}$

Numbers of years employed as a health worker $(n=280)$

$\begin{array}{llll}1-4 \text { years } & 54(19) & 19(35) & 35(65) \\ 5-9 \text { years } & 112(40) & 43(38) & 69(62) \\ 10-14 \text { years } & 53(19) & 13(25) & 40(75) \\ 15+\text { years } & 61(22) & 22(36) & 39(64)\end{array}$

Age group of health workers $(n=279)$

$\begin{array}{llll}21-25 \text { years } & 19(7) & 6(32) & 13(68) \\ 26-30 \text { years } & 76(27) & 26(34) & 50(66) \\ 31-35 \text { years } & 71(25) & 26(37) & 45(63) \\ 36-40 \text { years } & 52(19) & 12(23) & 40(77) \\ 41+\text { years } & 61(22) & 25(41) & 36(59)\end{array}$

Healthcare worker trained to conduct cervical cancer screening $(n=283)$

\begin{tabular}{|c|c|c|c|}
\hline Yes & 93 (33) & $25(27)$ & $68(73)$ \\
\hline No & $190(67)$ & $72(38)$ & $117(62)$ \\
\hline
\end{tabular}

HC has education material about cervical cancer $(n=283)$

$\begin{array}{llll}\text { Yes } & 84(30) & 24(29) & 60(79) \\ \text { No } & 200(70) & 74(37) & 125(63)\end{array}$

HC has guideline for cervical cancer screening $(n=280)$

$\begin{array}{llll}\text { Yes } & 58(21) & 21(36) & 37(64) \\ \text { No } & 222(79) & 75(34) & 147(66)\end{array}$

$\mathrm{HC}$ has HPV vaccination guideline $(n=275)$

\begin{tabular}{|c|c|c|c|}
\hline Yes & $204(74)$ & $67(33)$ & $137(67)$ \\
\hline No & $71(26)$ & $29(41)$ & $42(59)$ \\
\hline
\end{tabular}

\begin{tabular}{llllll}
1 & & \multicolumn{1}{c}{1} & & \\
0.82 & $0.46-1.46$ & 0.51 & 0.56 & $0.28-1.16$ & 0.12 \\
0.56 & $0.29-1.07$ & 0.08 & 0.55 & $0.25-1.22$ & 0.14
\end{tabular}

1

$1.17 \quad 0.60-2.30 \quad 0.64$

1

$\begin{array}{llllll}1.19 & 0.67-2.12 & 0.55 & 1.25 & 0.65-2.43 & 0.51\end{array}$

$\begin{array}{llllll}1 & & & 1 & & \\ 0.87 & 0.44-1.71 & 0.69 & 1.1 & 0.44-2.72 & 0.84 \\ 1.67 & 0.72-3.86 & 0.23 & 3.17 & 0.96-10.54 & 0.06 \\ 0.96 & 0.45-2.07 & 0.92 & 2.91 & 0.68-12.47 & 0.15\end{array}$

$1 .-1$

$\begin{array}{llllll}0.89 & 0.30-2.61 & 0.83 & 1.02 & 0.28-3.67 & 0.98\end{array}$

$\begin{array}{llllll}0.8 & 0.27-2.35 & 0.68 & 0.65 & 0.15-2.76 & 0.56\end{array}$

$1.54 \quad 0.48-4.92 \quad 0.47 \quad 0.92 \quad 0.20-4.14 \quad 0.91$

$0.66 \quad 0.22-1.98 \quad 0.46 \quad 0.27 \quad 0.05-1.58 \quad 0.15$

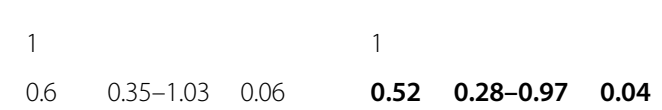

$\begin{array}{llllll}0.6 & 0.35-1.03 & 0.06 & \mathbf{0 . 5 2} & \mathbf{0 . 2 8}-\mathbf{0 . 9 7} & \mathbf{0 . 0 4}\end{array}$

1

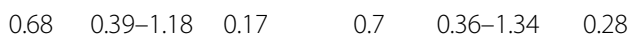

1

$\begin{array}{llllll}1.11 & 0.61-2.03 & 0.73 & 1.34 & 0.64-2.77 & 0.44\end{array}$

COR Crude Odds Ratio, AOR Adjusted Odds Ratio. Adjusted for each demographic characteristic. Bolded figures indicate statistically significant variables at $p \leq$ 0.05 . HC Health centre. We used Hosmer-Lemeshow goodness-of-fit test to check if our final model had fitted the data perfectly well and the $p$-value $=0.85$ from the Hosmer-Lemeshow's goodness-of-fit test is an indicator that our model fitted the data well. The few missing data on demographic characteristics were not dropped from the analysis since the missing rates were less than $5 \%$ and were considered inconsequential based on Schafer (1999)

cancer. Yet, only 46 (16\%) knew the correct target age group for cervical cancer screening using VIA that is recommended by Uganda Ministry of Health [7]. Furthermore, we found that some participants had misconceptions about cervical cancer risk factors, signs, and symptoms such as infection with HSV-2, having a family history of cervical cancer, over consumption of alcohol, abdominal pain, having a headache and having night sweats. The lack of knowledge on the age group recommended for cervical cancer screening using VIA, and the misconceptions exhibited by some health workers on the risk factors, signs, and symptoms of cervical cancer, need to be addressed as it is likely to have negative effects for any future preventive programmes. This is because 
health workers such as nurses, midwives, and clinical officers form most of the health workforce in Uganda and interface more frequently with patients and the community. Their accurate understanding of the age group recommended for cervical cancer screening, risk factors, signs, and symptoms is essential for providing correct health education messages to the patients and the community they serve.

Our study demonstrates that participants who were not trained to conduct cervical cancer screening were $61 \%$ more likely to have inadequate knowledge about cervical cancer than those who were trained. Studies conducted among health workers reported that attending training for cervical cancer prevention and treatment was significantly associated with an increase in knowledge $[53,65]$. Unlike the study conducted in Tanzania which showed that younger nurses were more likely to have adequate knowledge about cervical cancer than older nurses [13], our study found no association between age of healthcare workers and their knowledge about cervical cancer. This could be because our study was conducted well after the Ugandan Ministry of Health had launched an HPV vaccination campaign in 2015 [5] and many of our participants were already made aware of cervical cancer.

In this study it was encouraging to find that most participants had positive attitudes towards participation in cervical cancer training, and prevention activities. About $88 \%$ of participants stated that they always advised their patients to be screened for cervical cancer. This is much higher compared with the findings from a study conducted in Cote d'Ivoire (38\%) [53].

Our study shows that participants who were not trained to conduct cervical cancer screening were $48 \%$ times less likely to have positive attitudes towards participation in cervical cancer training, and prevention activities than participants who indicated they were trained to conduct cervical cancer screening. Given the role health workers play in providing health education about cervical cancer, there is need to increase coverage of training for health workers about cervical cancer so that negative attitudes can be changed.

Most of the female health workers in our study had been previously screened for cervical cancer. Other studies have documented a much lower uptake of cervical cancer screening by female health workers than in our study and those ranged from 6 to $41 \%[8,13,53,54,56$, 57, 61-63, 66-73]. Female health workers who were not screened for cervical cancer cited various reasons for not attending screening including lack of access to screening services, misbeliefs about cervical cancer and screening, fear of the results and nonchalant attitude towards screening for cervical cancer. Previous studies have reported similar observations about female health workers' lack of undertaking cervical cancer screening $[8,57,58$, $62,63,68,69,71-74]$.

In our study, participants' qualifications were not associated with knowledge of cervical cancer. However, a study conducted in Cameroon found that cervical cancer knowledge was significantly associated with health workers' qualifications [70]. This difference could be because, in the Cameroonian study, other participants such as doctors and students studying medicine, nursing and midwifery were included in that study.

\section{Limitations}

Our study was a cross-sectional study requiring participants to recall past events and this fact could have resulted in recall bias. More women could have responded that they have ever been screened for cervical cancer due to social desirability bias. However, social desirability bias was addressed by ensuring that the questionnaire had participants' number but no name. This gave confidence to the participants when completing the questionnaire as they were aware the information was anonymous. Participants were reassured that the information provided would be kept confidential and were encouraged to be as honest as possible while filling in the questionnaire. The study findings may not be generalised to all the nurses, midwives, and clinical officers in Uganda since the sample size was modest at 286. Furthermore, the findings may not be generalised to nurses, midwives and clinical officers who are working in referral hospitals or in private health facilities in Northern Uganda as their employers could have trained them and provided them with Strategic Plan for Cervical Cancer Prevention and Control in Uganda.

\section{Strength of the study}

This study is the first to examine health workers' knowledge, attitudes, and practice of cervical cancer prevention among rural health workers in Northern Uganda. The questionnaires were answered in the presence of the PI or a research assistant and this prevented health workers from discussing answers among themselves or searching information online.

\section{Conclusion}

Our study demonstrates that there were negative attitudes and misconceptions about cervical cancer risk factors, signs, and symptoms among rural health workers as result of lack of knowledge about cervical cancer.

As part of a comprehensive strategy to achieve Sustainable Development Goal (SDG) target 3.4 which aims to reduce premature death by one third by 2030 from non-communicable diseases [23], SSA governments must develop training programme of rural health workers to improve their knowledge, attitudes, and 
practical skills in cervical cancer screening and treatment of precancerous lesions. Furthermore, training health workers to improve their practical skills in conducting cervical cancer screening and treatment of precancerous lesions will ensure that health workers are able to provide these services to women as part of the WHO triple-intervention by 2030 and beyond [23]. Uganda and other low-resource countries need to develop and disseminate cervical cancer prevention guidelines and health education materials which can be used by rural health workers to ensure standardise quality of services provided by rural health workers.

\section{Supplementary Information}

The online version contains supplementary material available at https://doi. org/10.1186/s12885-021-07847-z.

Additional file 1. Study questionnaire

\section{Abbreviations \\ AOR: Adjusted odds ratio; Cl: Confidence interval; CO: Clinical Officer; COR: Crude odds ratio; df: Degree of freedom; DLG: District local government; HC: Health centre; HIV/AIDS: Human immunodeficiency virus/ Acquired immunodeficiency syndrome; HPV: Human papillomavirus; NGOs: Non-governmental organizations; OR: Odds ratio; Pap: Papanicolaou; PI: Principal investigator; TASO: The AIDS Support Organization; SSA: Sub- Sahara African; VIA: Visual inspection with acetic acid; WHO: World Health Organization}

\section{Acknowledgements}

James Henry Obol is currently pursuing a PhD study in public health from UNSW and was awarded University International Postgraduate Award Scholarship and received funding for data collection from the NORHED PROJECT, SURVIVAL PLUSS, Gulu University. James Henry Obol is grateful for all the financial support provided by all stakeholders to enable me pursues a PhD study.

\section{Authors' contributions}

$\mathrm{JHO}$ is $\mathrm{Pl}$ and conceived the study, wrote the proposal, collected data, performed data analysis, interpretation reviewed the literature and wrote the manuscript. SL participated in interpreting results and reviewing literature. MJO participated in editing data collection tool and carried out field data collection. RH participated in editing proposal, editing data collection tool, interpreting results and reviewed literature and RR participated in editing proposal, editing data collection tool, interpreting results and reviewed literature. All the authors reviewed drafts and approved the final manuscript.

\section{Funding}

Obol received partial funding for data collection from the NORHED PROJECT, SURVIVAL PLUSS, Gulu University. The funder has no role in the conduct and reporting of the research findings.

\section{Availability of data and materials}

The datasets generated and/or analysed during the current study are available in the Zenodo repository: https://doi.org/10.5281/zenodo.3722791

\section{Ethics approval and consent to participate}

The following institutions granted ethical approval for the study: UNSW Human Research Ethics Committee (HC180508), Gulu University Research Ethics Committee (GUREC-090-18) and Uganda National Council for Science and Technology (SS4839). Administrative clearances to conduct the study were granted by each of the eight district local governments. Each participant provided written informed consent to participate in the study.

\section{Consent for publication}

Not applicable.

\section{Competing interests}

The authors declared no competing interests.

Received: 22 July 2020 Accepted: 27 January 2021

Published online: 03 February 2021

\section{References}

1. Bruni L, Albero G, Serrano B, Mena M, Gómez D, Muñoz J, Bosch F, de Sanjosé S: ICO/IARC Information Centre on HPV and Cancer (HPV Information Centre). Human Papillomavirus and Related Diseases in the World. Summary Report 17 June 2019. 2019. From https://www.hpvcentre. net/statistics/reports/XWX.pdf. Accessed on 29 Aug 2019

2. Jacques Ferlay IS, Dikshit R, Eser S, Mathers C, Rebelo M, Parkin DM, Forman D, Bray F. Cancer incidence and mortality worldwide: sources, methods and major patterns in GLOBOCAN 2012. Int J Cancer. 2014;136:29. https://doi. org/10.1002/ijc.29210.

3. De Vuyst H, Alemany L, Lacey C, Chibwesha CJ, Sahasrabuddhe V, Banura C, Denny L, Parham GP. The burden of human papillomavirus infections and related diseases in sub-saharan Africa. Vaccine. 2013;31 Suppl 5(0 5):F32-46. https://doi.org/10.1016/j.vaccine.2012.07.092

4. Bruni L, Albero G, Serrano B, Mena M, Gómez D, Muñoz J, Bosch F, de Sanjosé S: ICO/IARC Information Centre on HPV and Cancer (HPV Information Centre). Human Papillomavirus and Related Diseases in Africa. Summary Report 17 June 2019. 2019. From https://hpvcentre.net/statistics/ reports/XFX.pdf. Accessed on 2/7/2020

5. GAVI. Gavi country factsheet: Uganda, vol. 2019: GAVl; 2019. From https:// www.gavi.org/country/fact-sheets/uganda.pdf. Accessed on 17 June 2019

6. Randall TC, Ghebre R. Challenges in prevention and care delivery for women with cervical Cancer in sub-Saharan Africa. Front Oncol. 2016;6(160): 160. https://doi.org/10.3389/fonc.2016.00160.

7. MoH: Strategic plan for cervical cancer prevention and control in Uganda 2010-2014. Edited by Health. Kampala: Ministry of Health; 2010:70. From http://www.iccp-portal.org/system/files/plans/PATH_Uganda_cxca_strat_ plan_2010-2014.pdf. Accessed on 15 Apr 2018

8. Mutyaba T, Mmiro FA, Weiderpass E. Knowledge, attitudes and practices on cervical cancer screening among the medical workers of Mulago hospital, Uganda. BMC Med Educ. 2006;6(1):13. https://doi.org/10.1186/1472-6920-613.

9. Tsu VD, Njama-Meya D, Lim J, Murray M, de Sanjose S. Opportunities and challenges for introducing HPV testing for cervical cancer screening in subSaharan Africa. Prev Med. 2018;114:205-8. https://doi.org/10.1016/j.ypmed. 2018.07.012.

10. Rudd P, Gorman D, Meja S, Mtonga P, Jere Y, Chidothe I, Msusa AT, Bates MJ, Brown E, Masamba L. Cervical cancer in southern Malawi: a prospective analysis of presentation, management, and outcomes. Malawi Med J. 2017; 29(2):124-9. https://doi.org/10.4314/mmj.v29i2.9.

11. Maseko FC, Chirwa ML, Muula AS. Health systems challenges in cervical cancer prevention program in Malawi. Glob Health Action. 2015;8(26282): 26282. https://doi.org/10.3402/gha.v8.26282.

12. Mwaka AD, Wabinga HR, Mayanja-Kizza H. Mind the gaps: a qualitative study of perceptions of healthcare professionals on challenges and proposed remedies for cervical cancer help-seeking in post conflict northern Uganda. BMC Fam Pract. 2013;14(193):14. https://doi.org/10.1186/ 1471-2296-14-193.

13. Urasa M, Darj E. Knowledge of cervical cancer and screening practices of nurses at a regional hospital in Tanzania. Afr Health Sci. 2011;11(1):48-57 PMC3092321.

14. Mwaka ADGC, Were EM, et al. Social, demographic and healthcare factors associated with stage at diagnosis of cervical cancer: cross-sectional study in a tertiary hospital in northern Uganda. BMJ Open. 2016;6. https://doi.org/ 10.1136/bmjopen-2015-007690.

15. Benemariya E, Chironda G, Nkurunziza A, Katende G, Sego R, Mukeshimana M. Perceived factors for delayed consultation of cervical cancer among women at a selected hospital in Rwanda: An exploratory qualitative study. Int J Afr Nurs Sci. 2018;9:129-35. https://doi.org/10.1016/j.jians.2018.10.006.

16. Wabinga HR, Nambooze S, Amulen PM, Okello C, Mbus L, Parkin DM. Trends in the incidence of cancer in Kampala, Uganda 1991-2010. Int J Cancer. 2014;135(2):432-9. https://doi.org/10.1002/ijc.28661.

17. Banura C, Mirembe FM, Katahoire AR, Namujiu PB, Mbonye AK, Wabwire FM. Epidemiology of HPV genotypes in Uganda and the role of the current 
preventive vaccines: a systematic review. Infect Agent Cancer. 2011;6(1):11 https://doi.org/10.1186/1750-9378-6-11.

18. Mukama T, Ndejjo R, Musabyimana A, Halage AA, Musoke D. Women's knowledge and attitudes towards cervical cancer prevention: a cross sectional study in eastern Uganda. BMC Womens Health. 2017;17(1):9. https://doi.org/10.1186/s12905-017-0365-3.

19. UDHS. Uganda Demographic and Health Survey 2016. In: Uganda Bureau of Statistics (UBOS) and ICF 2018 Uganda Demographic and Health Survey 2016 Kampala, Uganda and Rockville, Maryland, USA: UBOS and ICF. Kampala: Uganda Bureau of Statistics (UBOS) and ICF 2018. p. 625. From https://dhsprogram.com/pubs/pdf/FR333/FR333.pdf. Accessed on 6/4/2018.

20. UAIDSC. Uganda HIV/AIDS country progress report July 2016-June 2017. In: THEME: "Reaching men, girls and young women to reduce new HIV infections". Uganda: Uganda AIDS Commission; 2017. p. 113. From https:// www.unaids.org/sites/default/files/country/documents/UGA_2018_ countryreport.pdf. Accessed on 30 July 2019

21. Nakisige C, Schwartz M, Ndira AO. Cervical cancer screening and treatment in Uganda. Gynecol Oncol Rep. 2017;20:37-40. https://doi.org/10.1016/j. gore.2017.01.009.

22. WHO. Uganda embarks on a multisectoral approach to improve Vaccination coverage against Human Papillomavirus. Uganda: WHO Regional Office for Africa; 2019. p. 1. From https://www.afro.who.int/news/uganda-embarksmultisectoral-approach-improve-vaccination-coverage-against-human. Accessed on 26 July 2019

23. Canfell K, Kim JJ, Brisson M, Keane A, Simms KT, Caruana M, Burger EA Martin D, Nguyen DTN, Bénard É, et al. Mortality impact of achieving WHO cervical cancer elimination targets: a comparative modelling analysis in 78 low-income and lower-middle-income countries. Lancet. 2020;395(10224): 591-603. https://doi.org/10.1016/S0140-6736(20)30157-4.

24. Heena H, Durrani S, AlFayyad I, Riaz M, Tabasim R, Parvez G, Abu-Shaheen A. Knowledge, attitudes, and practices towards cervical Cancer and screening amongst female healthcare professionals: a cross-sectional study. J Oncol. 2019;2019:5423130. https://doi.org/10.1155/2019/5423130.

25. Arulogun OS, Maxwell OO. Perception and utilization of cervical cancer screening services among female nurses in University College Hospital, Ibadan, Nigeria. Pan Afr Med J. 2012;11:69. https://doi.org/10.11604/pamj. 2012.11.69.1580.

26. Brisson M, Kim JJ, Canfell K, Drolet M, Gingras G, Burger EA, Martin D, Simms KT, Bénard É, Boily M-C, et al. Impact of HPV vaccination and cervical screening on cervical cancer elimination: a comparative modelling analysis in 78 low-income and lower-middle-income countries. Lancet. 2020; 395(10224):575-90. https://doi.org/10.1016/S0140-6736(20)30068-4.

27. Julian H, Ronald RA. Developing a Land Conflict Monitoring and Mapping Tool for the Acholi Sub-Region of Northern Uganda; 2015. p. 21. From https://landportal.org/library/resources/issn-2051-0926/developing-landconflict-monitoring-and-mapping-tool-acholi-sub. Accessed on 24 Apr 2020

28. Namakula J, Witter S. Living through conflict and post-conflict: experiences of health workers in northern Uganda and lessons for people-centred health systems. Health Policy Plan. 2014;29(suppl_2):ii6-ii14. https://doi.org/ 10.1093/heapol/czu022.

29. Mukasa N. War-child mothers in northern Uganda: the civil war forgotten legacy. Dev Pract. 2017;27(3):354-67. https://doi.org/10.1080/09614524.2017. 1294147.

30. $\mathrm{MoH}$. Health and mortality survey among internally displaced persons in Gulu, Kitgum and Pader districts, northern Uganda. Uganda: Ministry of Health Uganda and World Health Organisation; 2005. p. 77. From http:// www.who.int/hac/crises/uga/sitreps/Ugandamortsurvey.pdf. Accessed on 26 May 2018

31. Malamba SS, Muyinda H, Spittal PM, Ekwaru JP, Kiwanuka N, Ogwang MD, Odong P, Kitandwe PK, Katamba A, Jongbloed K, et al. "The Cango Lyec Project - healing the elephant": HIV related vulnerabilities of post-conflict affected populations aged 13-49 years living in three mid-northern Uganda districts. BMC Infect Dis. 2016;16(1):690. https://doi.org/10.1186/s12879-0162030-0.

32. Dodge CP. Health implications of war in Uganda and Sudan. Soc Sci Med. 1990;31(6):691-8. https://doi.org/10.1016/0277-9536(90)90251-m.

33. Chi PC, Bulage $P$, Urdal H, Sundby J. Perceptions of the effects of armed conflict on maternal and reproductive health services and outcomes in Burundi and northern Uganda: a qualitative study. BMC Int Health Hum Rights. 2015;15(1):7. https://doi.org/10.1186/s12914-015-0045-z.
34. MoH: National Health Facility Master List 2018. Edited by Information DoH. Kampala: Ministry of Health Uganda; 2018:164. From http://library.health.go. ug/publications/health-facility-inventory/national-health-facility-master-list-2 018. Accessed on 15 Jan 2019

35. MoH: HEALTH SECTOR STRATEGIC \& INVESTMENT PLAN: Promoting People's Health to Enhance Socio-economic Development. 2010/11-2014/15. Kampala: Ministry of Health; 2010. From http://library.health.go.ug/ publications/policy-documents/health-sector-strategic-investment-planpromoting-people\%E2\%80\%99s-health. Accessed on 27 Oct 2020

36. $\mathrm{MoH}$. Second National Health Policy: Promoting People's Health to Enhance Socio-economic Development. Kampala: Ministry of Health; 2010. p. 44. From http://library.health.go.ug/publications/leadership-and-governancegovernance/policy-documents/national-health-policy. Accessed on $14 \mathrm{Apr}$ 2018

37. MoH: Guidelines to the Local Government Planning Process Health Sector Supplement. Edited by Uganda MoH. Kampala: Ministry of Health;2019:70. From http://library.health.go.ug/publications/guidelines/guidelines-localgovernment-planning-process-health-sector-supplement-july. Accessed on 15 Oct 2019

38. MoH: Approved Staffing Norms at various level. Edited by Health Mo. Uganda: Ministry of Health Uganda; 2014. From http://library.health.go.ug/ publications/health-workforce/human-resource-management/approvedstaffing-norms-various-levels. Accessed on 27 July 2018

39. Mays DC, O'Neil EJ, Mworozi EA, Lough BJ, Tabb ZJ, Whitlock AE, Mutimba EM, Talib ZM. Supporting and retaining village Health teams: an assessment of a community health worker program in two Ugandan districts. Int J Equity Health. 2017;16(1):129. https://doi.org/10.1186/s12939-017-0619-6.

40. Nanyonjo A, Kertho E, Tibenderana J, Källander K. District Health Teams' readiness to institutionalize integrated community case Management in the Uganda Local Health Systems: a repeated qualitative study. Global Health Sci Pract. 2020;8(2):190-204. https://doi.org/10.9745/GHSP-D-19-00318.

41. MoH: Master Health Facilities Inventory. 2012. From http://library.health.go. ug/sites/default/files/resources/Health\%20Facility\%20Inventory\%20update\%2 0july\%202012.pdf. Accessed on 20 May 2018

42. MoH: Health Sector Strategic Plan III 2010/11-2014/15. In. Edited by Health. Kampala; 2010. From https://www.health.go.ug/docs/HSSP_III_2010.pdf. Accessed on 15 Oct 2019

43. MoH. Ministry of Health Uganda: Sector Grant and Budget Guidelines to Facilities for FY 2020/21; 2020. p. 35. From https://budget.go.ug/sites/ default/files/HEALTH\%20FACILITY\%20GUIDELINES.pdf. Accessed on 26 Oct 2020

44. Acup C, Bardosh KL, Picozzi K, Waiswa C, Welburn SC. Factors influencing passive surveillance for $\mathrm{T}$. b. rhodesiense human african trypanosomiasis in Uganda. Acta Trop. 2017;165:230-9. https://doi.org/10.1016/j.actatropica. 2016.05.009.

45. MPS. Job Descriptions and Specifications for Jobs in Local Governments. Kampala: Ministry of Public Service - Uganda; 2011. p. 482. From https://psc. go.ug/sites/default/files/downloads/Local\%20Government\%20Job\%2 ODescription\%20.pdf. Accessed on 15 May 2019

46. MoH: Health sector development plan 2015/16-2019/20. Edited by Health. Kampala;2015:110. From http://health.go.ug/sites/default/files/Health\%2 OSector\%20Development\%20Plan\%202015-16_2019-20.pdf. Accessed on 12 Apr 2018

47. Leslie K. Survey Sampling. New York: Wiley; 1965. p. xvi, 643. \$10.95. https:// doi.org/10.1017/S0003055400132113.

48. StatTrek. Teach yourself statistics. From https://stattrek.com/statistics/ random-number-generator.aspx\#error. Accessed on 15 Sept 2019

49. Bruni L B-RL, Albero G, Aldea M, Serrano B, Valencia S, Brotons M, Mena M, Cosano R, Muñoz J, Bosch FX, de Sanjosé S, Castellsagué X Human Papillomavirus and Related Diseases in Uganda. Human Papillomavirus and Related Diseases in Uganda. In: Summary Report 27 July 2017. Institut Català d'Oncologia, L'Hospitalet de Llobregat (Barcelona, Spain): ICO/IARC Information Centre on HPV and Cancer (HPV Information Centre); 2017. From http://www.hpvcentre.net/statistics/reports/UGA_FS.pdf. Accessed on 29 Mar 2019.

50. Brinton LA, Hamman RF, Huggins GR, Lehman HF, Levine RS, Mallin K, Fraumeni JF. Sexual and reproductive risk-factors for invasive squamous-cell cervical-Cancer. J Natl Cancer Inst. 1987;79(1):23-30. https://doi.org/10.1093/ jnci/79.1.23.

51. Plummer M, Herrero R, Franceschi S, Meijer CJ, Snijders P, Bosch FX, de Sanjose S, Munoz N. Group IM-cCCS: smoking and cervical cancer: pooled 
analysis of the IARC multi-centric case--control study. Cancer Causes Control. 2003;14(9):805-14. https://doi.org/10.1023/b:caco.0000003811.98261. 3e.

52. Moreno V, Bosch FX, Munoz N, Meijer CJ, Shah KV, Walboomers JM, Herrero R, Franceschi S, International Agency for Research on Cancer. Multicentric Cervical Cancer Study G: effect of oral contraceptives on risk of cervical cancer in women with human papillomavirus infection: the IARC multicentric case-control study. Lancet. 2002;359(9312):1085-92. https://doi. org/10.1016/S0140-6736(02)08150-3.

53. Tchounga BK, Jaquet A, Coffie PA, Horo A, Sauvaget C, Adoubi I, Guie P, Dabis F, Sasco AJ, Ekouevi DK. Cervical cancer prevention in reproductive health services: knowledge, attitudes and practices of midwives in cote d'Ivoire, West Africa. BMC Health Serv Res. 2014;14(1):165. https://doi.org/10. 1186/1472-6963-14-165.

54. Dulla D, Daka D, Wakgari N. Knowledge about cervical cancer screening and its practice among female health care workers in southern Ethiopia: a crosssectional study. Int J Women's Health. 2017;9:365-72. https://doi.org/10. 2147/IJWH.S132202.

55. Ndizeye Z, Vanden Broeck D, Vermandere H, Bogers JP, Van Geertruyden JP. Knowledge and practices of general practitioners at district hospitals towards cervical cancer prevention in Burundi, 2015: a cross-sectional study. Glob Health. 2018;14(1):4. https://doi.org/10.1186/s12992-018-0321-5.

56. Kress CM, Sharling L, Owen-Smith AA, Desalegn D, Blumberg HM, Goedken J. Knowledge, attitudes, and practices regarding cervical cancer and screening among Ethiopian health care workers. Int J Women's Health. 2015;7:765-72. https://doi.org/10.2147/IJWH.S85138.

57. Anyebe EE, Opaluwa SA, Muktar HM, Philip F. Knowledge and practice of cervical Cancer screening amongst nurses in Ahmadu Bello University teaching hospital Zaria. Res Humanit Soc Sci. 2014;4(27):9 ISSN: 2225-0484.

58. Oche MO, Kaoje UM, Gana G, Ango JT. Cancer of the cervix and cervical screening: current knowledge, attitude and practices of female health workers in Sokoto, Nigeria. Int J Med Med Sci. 2013;5(4):184-90. https://doi. org/10.5897/IJMMS2013.0886.

59. Christiansen T, Lauritsen J. EpiData - Comprehensive Data Management and Basic Statistical Analysis System, vol. 3.1. Odense Denmark: EpiData Association; 2010. From http://www.epidata.dk. Accessed on 15 Dec 2018

60. StataCorp. Stata Statistical Software: Release 16. College Station: StataCorp LLC; 2019. from https://www.stata.com/. Accessed on 15 May 2019

61. Udigwe GO. Knowledge, attitude and practice of cervical cancer screening (pap smear) among female nurses in Nnewi, south eastern Nigeria. Niger J Clin Pract. 2006;9(1):40-3 PMID: 16986288.

62. Ayinde $\mathrm{OA}$, Omigbodun $\mathrm{AO}$. Knowledge, attitude and practices related to prevention of cancer of the cervix among female health workers in Ibadan. J Obstet Gynaecol. 2003;23(1):59-62. https://doi.org/10.1080/ 0144361021000043272

63. Anantharaman V, Sudharshini S, Chitra A. A cross-sectional study on knowledge, attitude, and practice on cervical cancer and screening among female health care providers of Chennai corporation, 2013. J Acad Med Sci. 2012:2(4):124-8. https://doi.org/10.4103/2249-4855.141132.

64. Haider S, Haq UN, Riaz S, Nasim A, Saood M, Yasmin R. Nurse's knowledge and Awareness Regarding Cervical Cancer and its Prevention in Different Hospitals of Quetta, Pakistan. Res Pharm Health Sci. 2018;14(1):436-41. https://doi.org/10.32463/rphs.2018.v04i01.06

65. Umuago IJ, Obiebi IP, Eze GU, Moeteke NS. Improving primary health care workers' knowledge of cervical cancer and visual inspection screening techniques through competency-based training: prospects for expanding coverage in developing countries. Int J Commun Med Public Health. 2020; 7(5):8. https://doi.org/10.18203/2394-6040.ijcmph20201960.

66. Can H, Erdem O, Oztekin C, Celik SB, Onde M, Celepkolu T, Ongel K. Are Primary Health Care Workers Aware of Cervical Cancer Risk? Asian Pac J Cancer Prev. 2014;15(16):6669-71. https://doi.org/10.7314/apjcp.2014.15.16. 6669.

67. Gharoro EP, Ikeanyi EN. An appraisal of the level of awareness and utilization of the pap smear as a cervical cancer screening test among female health workers in a tertiary health institution. Int J Gynecol Cancer. 2006;16(3):1063. https://doi.org/10.1136/ijgc-00009577-200605000-00018.

68. Eze GU, Obiebi IP, Umuago IJ. Perspectives of cervical cancer and screening practices among staff of a teaching hospital in South-South Nigeria. J Cancer Res Pract. 2018;5(2):67-73. https://doi.org/10.1016/j.jcrpr.2018.01.001.

69. Tran NT, Taylor R, Choe IS, Pyo SH, Kim SO, So CH. Knowledge, attitude and practice (KAP) concerning cervical Cancer and screening among rural and urban female healthcare practitioners in the democratic People's Republic of Korea. Asian Pac J Cancer Prev. 2011;12(11):3023-8 ISSN: 1513-7368.

70. McCarey C, Pirek D, Tebeu PM, Boulvain M, Doh AS, Petignat P. Awareness of HPV and cervical cancer prevention among Cameroonian healthcare workers. BMC Womens Health. 2011;11(1):45. https://doi.org/10.1186/14726874-11-45.

71. Yörük S, Açikgöz A, Türkmen H, Ergör G. Risk factors and relationship between screening periodicity and risk of cervical cancer among nurses and midwives. A cross-sectional study. Sao Paulo Med J. 2019;137:119-25. https://doi.org/10.1590/1516-3180.2018.0244230119.

72. Gebreegziabher M, Asefa NG, Berhe S. Factors affecting the practices of cervical Cancer screening among female nurses at public Health institutions in Mekelle town, northern Ethiopia, 2014: a cross-sectional study. J Cancer Res. 2016;2016:7. https://doi.org/10.1155/2016/4743075.

73. Gol I, Erkin O. Knowledge and practices of nurses on cervical cancer, HPV and HPV vaccine in Cankiri state hospital, Turkey. J Pak Med Assoc. 2016; 66(12):1621-6 ISSN: 0030-9982.

74. Tay K, Tay SK, Tesalona KC, Rashid NMR, Tai EYS, Najib SJM. Factors affecting the uptake of cervical cancer screening among nurses in Singapore. Int J Gynecol Obstet. 2015;130(3):230-4. https://doi.org/10.1016/j.ijgo.2015.03.037.

\section{Publisher's Note}

Springer Nature remains neutral with regard to jurisdictional claims in published maps and institutional affiliations.

\section{Ready to submit your research? Choose BMC and benefit from:}

- fast, convenient online submission

- thorough peer review by experienced researchers in your field

- rapid publication on acceptance

- support for research data, including large and complex data types

- gold Open Access which fosters wider collaboration and increased citations

- maximum visibility for your research: over $100 \mathrm{M}$ website views per year

At $\mathrm{BMC}$, research is always in progress.

Learn more biomedcentral.com/submissions 